\section{Immunotherapy alliance for T1D}

\author{
By Kai-Jye Lou, Staff Writer
}

Novo Nordisk A/S has partnered with JDRF to help populate the pharma's newly opened Type 1 Diabetes R\&D Center in Seattle with early stage projects. The center will run side-by-side comparisons of technologies being developed through the foundation's sponsored projects as well as other opportunities the partners identify. A joint committee will select the most promising for further development by the pharma.

Novo Nordisk formed the Type 1 Diabetes R\&D Center in January and opened its doors in June. The company plans to employ 20 immunotherapy researchers at the center, which is being led by Matthias von Herrath. He previously was director of the Center for Type 1 Diabetes Research at the La Jolla Institute for Allergy \& Immunology.

Under a June deal, Novo Nordisk and JDRF will work together for at least two years and will focus on immunotherapies for type 1 diabetes (T1D). Initial research could include JDRFfunded projects from academic groups, biotechs and undisclosed programs from the pharma's internal research pipeline, as well as other opportunities identified by the partners.

For top candidates coming from academia or Novo Nordisk, the partners will run additional preclinical and IND-enabling studies, after
"JDRF brings to the table its network of research partners from academia and industry and the supporting databases of information it has on the history and natural progression of type 1 diabetes."

-Matthias von Herrath, Novo Nordisk A/S build a pipeline of early stage technologies for type 1 diabetes and move them across the translational gap. "JDRF brings to the table its network of research partners from academia and industry and the supporting databases of information it has on the history and natural progression of type 1 diabetes," he told SciBX.

JDRF's databases include information from both clinical and preclinical studies.

“JDRF doesn't have its own laboratories, so we haven't had a good way to make direct comparisons between research projects evaluating different therapeutic approaches for type 1 diabetes," added Insel. "Novo Nordisk's Type 1 Diabetes R\&D Center will let us assess and make sideby-side comparisons on the scientific validity, technical feasibility and commercial viability of various immunotherapeutic strategies being developed for type 1 diabetes."

Milestones for the Novo Nordisk-JDRF deal and details of specific targets, compounds and projects are undisclosed. The pharma has not disclosed any immunotherapy programs for type 1 diabetes in its pipeline.

The partners have not yet selected any projects for the R\&D center and are not disclosing when they plan to start the first comparison studies. They are not providing metrics on the number of candidates they expect to compare and select for further development once the operation is ramped up.

Although specific financial details of the $\mathrm{R} \& \mathrm{D}$ collaboration are not being disclosed, von Herrath said the flow of money "will be from Novo Nordisk to JDRF and not the other way around."

Funding for existing JDRF-sponsored research projects not selected for development at the R\&D center will not be affected.

\section{A space with opportunities}

Von Herrath said one of the key obstacles in developing immunotherapies for type 1 diabetes is the need to measure up to the safety and which they will decide whether to take the candidate into clinical trials. For these projects, clinical development will be driven primarily by the pharma. For candidates from biotech companies, the pharma will provide the company with resources to accelerate progress, such as funding support and access to the R\&D center's facilities.

JDRF CSO Richard Insel said projects at the R\&D center also could include external research that has not previously received funding from JDRF. He added that the partners also plan to look at technologies and therapies being developed for other diseases that could be repurposed for type 1 diabetes, especially immunotherapies for other autoimmune and allergic conditions.

Rights to existing IP for projects picked up under the collaboration will be retained by the project investigator. Licensing issues and rights to new IP generated from projects under the collaboration will be negotiated on a project-by-project basis.

Von Herrath said the deal establishes a system for the partners to efficacy of available chronic therapies, such as insulin. Indeed, broadly immunosuppressive drugs such as cyclosporine A cannot be chronically used in the indication because they leave patients highly susceptible to infection and their long-term use increases the risk of cancer.

Thus, von Herrath said one class of immunotherapies the partners will consider is antigen-specific vaccines.

"Antigenic vaccines work by augmenting regulatory $\mathrm{T}$ cell activity and have site-specific activity," he told SciBX. "These properties make them very attractive for use in type 1 diabetes as they locally suppress both general inflammation and the immune response against the targeted autoantigen without causing systemic immunosuppression."

$\mathrm{T}_{\text {reg }}$ cells suppress the activity of autoreactive T cells, which attack and destroy insulin-producing pancreatic $\beta$ cells in type 1 diabetes.

The partners also are interested in picking up projects related to biomarkers that can be used to predict and evaluate treatment response and monitor disease progression. 


\section{ANALYSIS}

Von Herrath noted that such projects could, for example, include developing a bioinformatics platform to parse the information contained within JDRF's databases and other databases. These projects could lead to better understanding of disease progression and aspects of the disease that could be targeted with immunotherapies and also could help better tailor therapies to the optimal patient group, he said.

\section{TRANSLATIONAL NOTES}

Lou, K.-J. SciBX 5(27); doi:10.1038/scibx.2012.695

Published online July 12, 2012

COMPANIES AND INSTITUTIONS MENTIONED

JDRF, New York, N.Y.

La Jolla Institute for Allergy \& Immunology, La Jolla, Calif. Novo Nordisk A/S (CSE:NVO; NYSE:NVO), Bagsvaerd, Denmark 